Portland State University

PDXScholar

$1-2-2018$

\title{
E-Cigarette Airflow Rate Modulates Toxicant Profiles and Can Lead to Concerning Levels of Solvent Consumption
}

Tetiana Korzun

Portland State University

Maryana Lazurko

Portland State University

Tetiana Korzun

Portland State University

Ian Munhenzva

Portland State University

Kelley Barsanti

University of California, Riverside

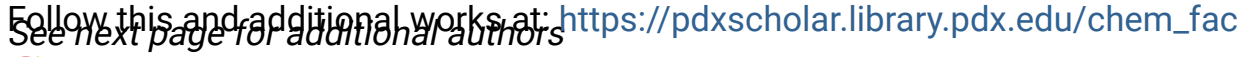

Part of the Medicinal-Pharmaceutical Chemistry Commons Let us know how access to this document benefits you.

\section{Citation Details}

Korzun, T., Lazurko, M., Munhenzva, I., Barsanti, K. C., Huang, Y., Jensen, R. P., ... \& Strongin, R. M. (2018). E-Cigarette Airflow Rate Modulates Toxicant Profiles and Can Lead to Concerning Levels of Solvent Consumption. ACS Omega, 3(1), 30-36.

This Article is brought to you for free and open access. It has been accepted for inclusion in Chemistry Faculty Publications and Presentations by an authorized administrator of PDXScholar. Please contact us if we can make this document more accessible: pdxscholar@pdx.edu. 


\section{Authors}

Tetiana Korzun, Maryana Lazurko, Tetiana Korzun, Ian Munhenzva, Kelley Barsanti, Yilin Huang, R. Paul Jensen, Jorge O. Escobedo, Wentai Luo, David H. Peyton, and Robert M. Strongin 


\section{E-Cigarette Airflow Rate Modulates Toxicant Profiles and Can Lead to Concerning Levels of Solvent Consumption}

Tetiana Korzun, ${ }^{\dagger}$ Maryana Lazurko, ${ }^{\dagger}$ Ian Munhenzva, ${ }^{\dagger}$ Kelley C. Barsanti, ${ }^{\ddagger}{ }^{\ddagger}$ Yilin Huang, R. Paul Jensen, ${ }^{\dagger}$ Jorge O. Escobedo, ${ }^{\dagger}$ Wentai Luo, ${ }^{\dagger, \S}$ David H. Peyton, ${ }^{\dagger}$ and Robert M. Strongin ${ }^{*}, \dagger \odot$

${ }^{\dagger}$ Department of Chemistry, Portland State University, 1719 SW 10th Avenue, Portland, Oregon 97201, United States

${ }^{\ddagger}$ Department of Chemical and Environmental Engineering, Center for Environmental Research and Technology, University of California-Riverside, 1084 Columbia Avenue, Riverside, California 92507, United States

${ }^{\S}$ Department of Civil and Environmental Engineering, Maseeh College of Engineering and Computer Science, Portland State University, 1930 SW 4th Avenue, Portland, Oregon 97201, United States

Supporting Information

ABSTRACT: Electronic cigarettes enabling enhanced airflow have grown in popularity in recent years. The objective of this study is to show that flow rates modulate the levels of specific aerosol toxicants produced in electronic cigarettes. Flow rates used in various laboratory investigations involving e-cigarettes have varied widely to date, and can thus promote interlaboratory variability in aerosol product profiles. The thermal decomposition of hydroxyacetone and glycolaldehyde is less favorable at lower temperatures, supporting the observations of these products at higher flow rates/lower heating coil temperatures. Higher temperatures promote the formation of acetaldehyde from hydroxyacetone and formaldehyde from both hydroxyacetone and glycolaldehyde. A separate finding is that greater airflow can also expose users to

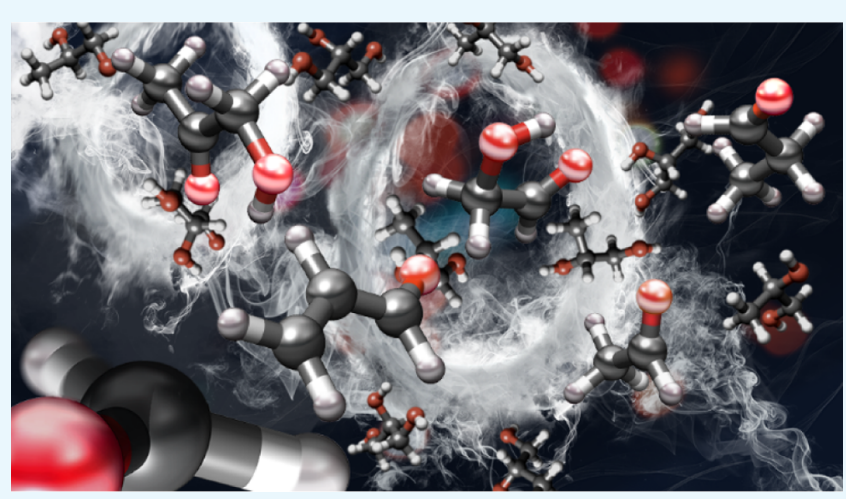
concerning levels of e-liquid solvents. Under the modest conditions studied, propylene glycol aerosol levels are found at above the acceptable inhalation levels defined by NASA, and in range of the generally recognized as safe levels for daily ingestion.

\section{INTRODUCTION}

Smoking is the second leading risk factor for early death and disability in the world. ${ }^{1}$ Most smokers initiate tobacco usage during adolescence. ${ }^{2}$ Recently, electronic cigarettes surpassed combustible cigarettes in popularity among youth in the United States, with one in six high school and middle school students reporting current use. ${ }^{3-5}$ It is thus concerning that the results of an extensive recent meta-analysis showed that electronic cigarettes are a strong, independent risk factor for smoking initiation among adolescents and young adults. ${ }^{6}$ Advocates claim that e-cigarettes deliver fewer toxins in lower doses to users compared to combustible cigarettes. However, such comparisons are of little relevance to the large number of young people using e-cigarettes before other tobacco products. 3,4

In addition, more basic research, beyond benchmarking ecigarette aerosol components and their biomarkers against those of combustible cigarettes, ${ }^{7}$ is needed to more completely assess potential health effects. For example, there is significant interlaboratory variation in the levels of e-cigarette aerosol products reported (Table S1, Supporting Information). In addition to a lack of standardized analytical protocols, this is attributable to multiple factors including the many custom e- liquid formulations, the frequent appearance of new device configurations on the market, variable heating coil morphology and related component properties, as well as individual user puffing topography patterns (Table 1), etc. Varying airflow rates, a significant component of puff topography, can differ widely among users, which can serve as a confounding element, hampering studies not only of topography but also of aerosol chemistry.

There are two common methods of inhaling e-cigarette aerosols. These are mouth-to-lung (MTL) and direct lung inhalation (DLI). MTL vaping is analogous to traditional cigarette and cigar smoking, wherein the user initially draws vapor into the mouth before inhaling into the lungs. In DLI, as the name implies, aerosol is inhaled directly into the lungs. MTL usage is generally performed with lower-power devices, with more restricted airflow, and affords less aerosol. DLI is for those wanting to optimize the amount of aerosol inhaled and the production of large "clouds." In general, DLI equipment consists of lower resistance (sub-ohm) coils, high-power

Received: October 9, 2017

Accepted: December 15, 2017

Published: January 2, 2018 
Table 1. Summary of Results of E-Cigarette Puff Topography Studies ${ }^{a, b}$

$\begin{array}{cllll}\begin{array}{c}\text { study } \\ \text { (reference) }\end{array} & \begin{array}{c}\text { puff } \\ \text { volume } \\ (\mathrm{mL})\end{array} & \begin{array}{c}\text { puff } \\ \text { duration } \\ (\mathrm{s})\end{array} & \begin{array}{c}\text { avg. flow rate } \\ (\mathrm{mL} / \mathrm{s})\end{array} & \begin{array}{c}\text { avg. number of puffs } \\ \text { (puffs/day) }\end{array} \\ 8 & \mathrm{NR} & 3.8 & \mathrm{NR} & 163 \\ 9 & 51 & 2.7 & 20 & \mathrm{NR} \\ 10 & \mathrm{NR} & \mathrm{NR} & \mathrm{NR} & 236 \\ 11 & \mathrm{NR} & \mathrm{NR} & \mathrm{NR} & 150 \\ 12 & \mathrm{NR} & 4.2 & \mathrm{NR} & \mathrm{NR} \\ 13 & \mathrm{NR} & 3.5 & \mathrm{NR} & \mathrm{NR} \\ 14 & 70 & 1.8 & 39 & \mathrm{NR} \\ 15 & \mathrm{NR} & 4.3 & \mathrm{NR} & \mathrm{NR} \\ 16 & 63 & 2.9 & 25 & \mathrm{NR} \\ 17 & 63,97 & 2.3,3.2 & 27,32 & \mathrm{NR} \\ 18 & 118 & 3.0 & 52 & \mathrm{NR} \\ 19 & 133 & 3.5 & 23,102 & 225 \\ 20 & 65 & 2.0 & 30 & 78 \\ 21 & 101 & 4.2 & 24 & \mathrm{NR}\end{array}$

${ }^{a}$ All of the values are averages taken from the listed references. ${ }^{b} \mathrm{NR}=$ not reported.

batteries, looser airflow, and higher proportions of glycerol/ propylene glycol (GLY/PG). Moreover, MTL vaping is typically preferred by ex-smokers. DLI is preferred by "cloud chasers," or vapers whose goal is to create large aerosol plumes. ${ }^{22}$ Cloud chasing has emerged as a competitive sport. Teens are often participants in cloud competitions. Evidence is emerging that, in addition to flavorings, cloud chasing and related "vapor tricks" are among the primary motivations for teen usage of e-cigarettes. ${ }^{22-25}$

To address, at least in part, the growing popularity of DLI and cloud chasing, the majority of currently available sub-ohm and rebuildable atomizers are fabricated with adjustable airflow. Airflow resistance and pressure drop are modulated by the aperture of the atomizer's air slits, affecting the airflow rate through the e-cigarette and its heating coil. ${ }^{26}$ Faster airflow lowers the heating coil temperature. ${ }^{27}$ However, despite its effects on the e-cigarette heating coil temperature, the influence of flow rate on aerosol toxin profiles and e-liquid consumption has not been formally investigated. Moreover, clinical studies have found that flow rates can vary among users, though most appear to fall within a range of $\sim 20$ to $\sim 39$ $\mathrm{mL} / \mathrm{s}$ (Table 1 ). The recent literature (Table 2) shows that there has been wide interlaboratory variability in the settings used by researchers for the factors of puff volume and puff duration, which together give rise to the airflow rate. We thus propose that differences in airflow rate can impact not only user exposure to inhalable toxins but also the variability in reported aerosol product profiles.

\section{RESULTS AND DISCUSSION}

Aerosol Product Profiles are a Function of Airflow Rate. Previous studies have mainly focused on the influence of heating coil temperature or operational voltage/wattage on eliquid enhanced toxicant production. ${ }^{28-30,32-36,41-44}$ Zhao has reported that flow rates are inversely related to heating coil temperatures. $^{27}$ One may thus assume that lower flow rates would lead to greater toxicant production. Interestingly, our data (Table 3) show that of the five aerosol products studied, glycolaldehyde and hydroxyacetone levels are lower when a lower flow rate is employed.
Table 2. Examples of Differing Flow Rates Used in Various Laboratory Investigations of E-Cigarette Aerosol Product Profiles

$\begin{array}{cccc}\begin{array}{c}\text { study } \\ \text { (reference) }\end{array} & \begin{array}{c}\text { puff volume } \\ (\mathrm{mL})\end{array} & \begin{array}{c}\text { puff duration } \\ (\mathrm{s})\end{array} & \text { flow rate }(\mathrm{mL} / \mathrm{s})^{a} \\ 28 & 50 & 5 & 10 \\ 29 & 50 & 3 & 17 \\ 30 & 55 & 4 & 14 \\ 31 & 55 & 2 & 28 \\ 32 & 70 & 1.8 & 39 \\ 33 & 70 & 1.8 & 39 \\ 34 & 55 & 3 & 18 \\ 35 & 50 & 3-4 & 13-17 \\ 36 & 55 & 2 & 28 \\ 37 & 50 & 4 & 13 \\ 38 & 70 & 3 & 23 \\ 39 & 40 & 4 & 10 \\ 40 & 500 & 60 & 8 \\ 41 & 91 & 4 & 23 \\ 42 & - & 8 & 19 \\ 43 & 40 & 4 & 10\end{array}$

${ }^{a}$ All of the flow rates were calculated values from puff volumes and duration, except for ref 42 where the data were available.

Previously, we reported that hydroxyacetone and glycolaldehyde were formed faster at relatively lower temperatures compared to all of the other PG/GLY aerosol products identified. ${ }^{44}$ Glycoladehyde is an oxidation product of GLY, formed via $\mathrm{H}$-abstraction to an oxygen radical followed by the $\mathrm{C}-\mathrm{C}$ bond scission (Scheme 1). Hydroxyacetone is formed mainly from the oxidation of PG (in addition, e.g., to the thermal dehydration of GLY). ${ }^{44}$ Moreover, glycolaldehyde and hydroxyacetone disappearance at lower airflow (hotter conditions) can be attributed to their thermal conversion to formaldehyde and acetaldehyde, respectively. For instance, it is well-known that acetaldehyde and formaldehyde levels increase in e-cigarette aerosols as a function of operational power.

The higher levels of propanal and acrolein observed under lower flow conditions (Table 3) are consistent with their formation via thermal dehydration reactions ${ }^{44}$ in which propanal and acrolein are the end products. Propanal and acrolein are well-known thermal dehydration products involving epoxide intermediates. Propanal is derived from PG via 2-methyloxirane, whereas acrolein arises from GLY via glycidol. $^{45,46}$

For the observed products, gas-phase Gibbs free energies of formation, $\Delta G_{\mathrm{f}, \mathrm{i}}^{\circ}\left(P^{\circ}=1 \mathrm{~atm}\right)$, are calculated using the ASTM Computer Program for Chemical Thermodynamic and Energy Release Evaluation (CHETAH) v.10 for $T=423-573 \mathrm{~K}$. For each reaction in Scheme 1, the reaction equilibrium constant is calculated from the estimated Gibbs free energy of reaction $\left(\Delta G_{\mathrm{rxn}}=\sum_{\mathrm{i} \text {, prod }} \Delta G_{\mathrm{f}, \mathrm{i}}^{\circ}+\sum_{\mathrm{i} \text {, react }} \Delta G_{\mathrm{f}, \mathrm{i}}^{\circ}\right)$ as follows: $K_{\mathrm{eq}}=-G_{\mathrm{rxn}} /$ $R T$, where $R=8.314 \times 10^{-3} \mathrm{~kJ} / \mathrm{mol} \mathrm{K}$. Table 4 lists $K_{\mathrm{eq}}$ as a function of temperature for the formation of propanal, acrolein, acetaldehyde, hydroxyacetone (via dehydration), and formaldehyde.

As the e-liquid is heated and evaporated, the e-liquid constituents are converted in the gas phase in proportions dependent on their concentrations in the mixture and their pure liquid vapor pressures. Assuming a liquid-phase equilibrium, composition (mole fraction basis) of 0.48 PG:0.48 GLY:0.05 $\mathrm{H}_{2} \mathrm{O}$ yields the gas-phase equilibrium 
Table 3. Concentrations of Aerosol Products in E-Liquid as a Function of Flow Rates at the Operational Power of 24 W

$\begin{array}{ccccccc}\text { coil } & \text { flow rate }(\mathrm{mL} / \mathrm{s}) & \text { propanal }(\mu \mathrm{g} / \mathrm{g}) & \text { acetaldehyde }(\mu \mathrm{g} / \mathrm{g}) & \text { acrolein }(\mu \mathrm{g} / \mathrm{g}) & \text { glycolaldehyde }(\mu \mathrm{g} / \mathrm{g}) & \text { hydroxyacetone }(\mu \mathrm{g} / \mathrm{g}) \\ 1 & 18.3 & 33.01 \pm 0.16 & 15.44 \pm 1.17 & 85.59 \pm 29.38 & 27.94 \pm 1.69 \\ 1 & 7.0 & 208.47 \pm 44.98 & 475.41 \pm 118.73 & 230.11 \pm 44.20 & 8.69 \pm 2.90 & 18.13 \pm 2.12 \\ 2 & 18.3 & 6.27 \pm 0.47 & 3.74 \pm 1.39 & 14.39 \pm 1.83 & 9.70 \pm 0.73 \\ 2 & 7.0 & 20.44 \pm 1.84 & 61.33 \pm 7.38 & 56.51 \pm 11.61 & 4.14 & 4.81 \pm 0.01\end{array}$

composition (mole fraction) shown in Table 5 as a function of temperature. These compositions approximate the initial conditions for oxidation and dehydration product formation in the gas phase.

Although the dehydration pathways are thermodynamically favorable across all heating temperatures (Table 4), at the lower heating temperatures there is a significant amount of gasphase water driving the reaction away from product formation (e.g., propanal and acrolein). At higher temperatures, the relative amounts of PG and GLY in the gas phase increase, promoting the amount of product formation at higher temperatures. This thermodynamic analysis supports the greater observed formation of propanal and acrolein at lower flow rates/higher heating temperatures. Thermal decomposition of hydroxyacetone and glycolaldehyde are not thermodynamically favored at lower temperatures (Table 4), supporting the observation of these products at higher flow rates/lower heating temperatures. As temperature increases, the formation of acetaldehyde from hydroxyacetone and formaldehyde from hydroxyacetone and glycolaldehyde become increasingly thermodynamically favorable, reaching positive values above $573 \mathrm{~K}$. Thermal decomposition of hydroxyacetone to form acetaldehyde is observed in this work at the lower flow rates/ higher heating temperatures. Although formaldehyde levels are not reported in this work, the thermodynamic favorability of its formation via thermal dehydration above $573 \mathrm{~K}$ supports the low levels of hydroxyacetone and glycolaldehyde observed at lower flow rates and or higher heating temperatures. The total amount of product observed in the collected aerosol (gas and particle phase) may also be affected by reactions in the condensed phase, as product formation may occur in the bulk e-liquid (followed by evaporation of the products) or in droplets as the vapor cools.

Increased Airflow Increases Solvent Consumption. It is known that the flow of air or gas across an evaporative surface increases the vaporization rates. ${ }^{48,49}$ Thus, power settings are not the sole factor to consider in enhancing vaporization. We measured the effect of airflow on aerosol consumption (Figure 1). As expected, a faster flow rate generally leads to less dense aerosols (Figure S2, Supporting Information), along with a greater PG/GLY consumption. The airflow rates investigated are $7.0,18.3$, and $36.0 \mathrm{~mL} / \mathrm{s}$. The intermediate $18.3 \mathrm{~mL} / \mathrm{s}$ flow is from the CORESTA standard. The $7.0 \mathrm{~mL} / \mathrm{s}$ value is chosen because it is the value required to activate one of the first-generation devices. ${ }^{26}$ The $36.0 \mathrm{~mL} / \mathrm{s}$ flow approximates a relatively high range reported in recent vaping topography investigations (Table 1). As mentioned above, newer-generation e-cigarettes allow for less restricted airflow. In our earlier investigation using an older e-cigarette, a maximum of just $11 \mathrm{mg}$ per puff of e-liquid was consumed at

Scheme 1. Summary of Major (but Not Exclusive) Pathways Leading to Products Formed Primarily via Either Dehydration (Acrolein and Propanal) or Oxidation (Glycolaldehyde and Hydroxyacetone) ${ }^{a}$

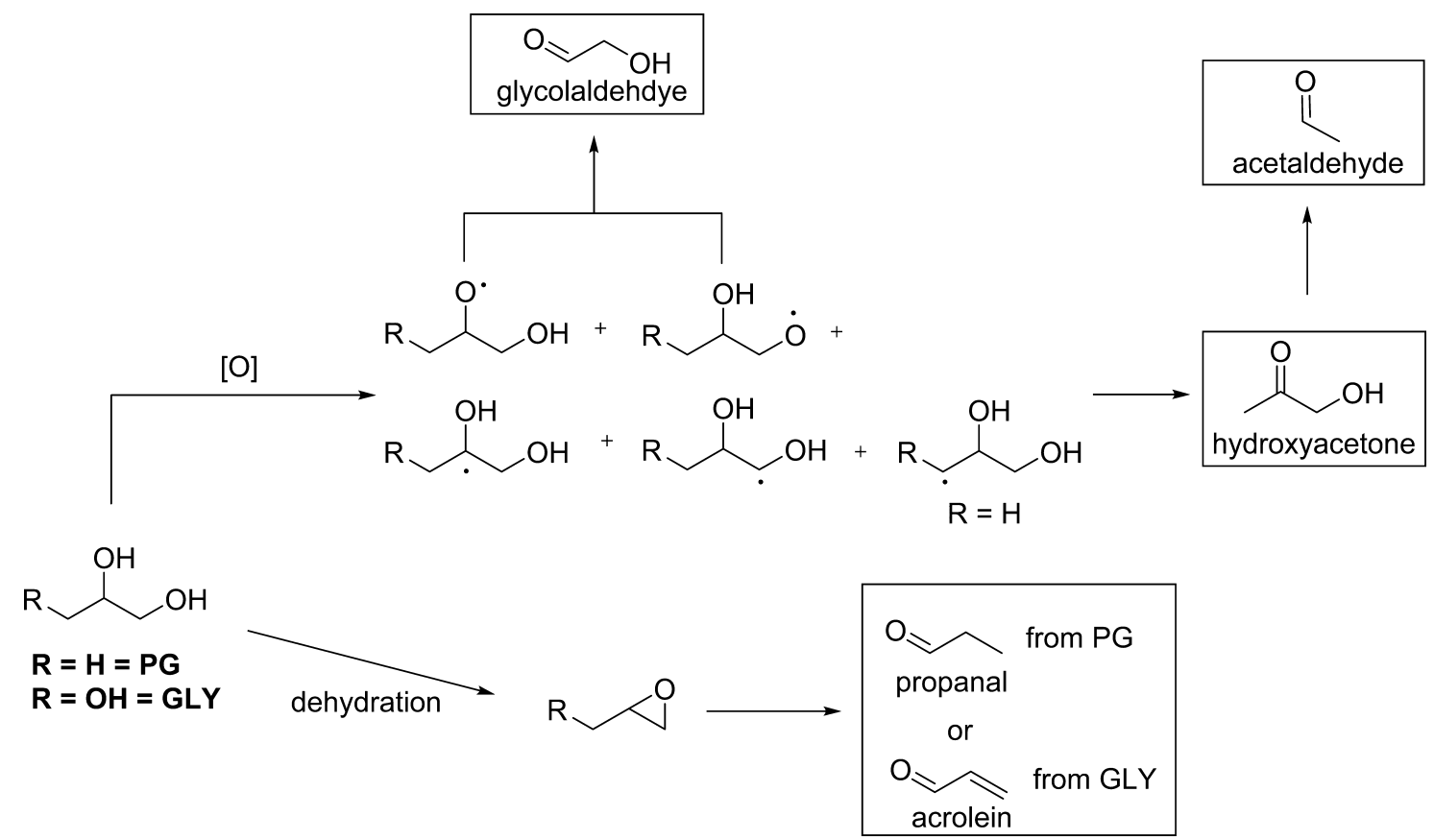

${ }^{a}$ Formaldehyde (not shown) is a byproduct of the formation of glycolaldehyde, hydroxyacetone, and acetaldehyde. One of several routes to hydroxyacetone has been reported to involve the dehydration of GLY; however, hydroxyacetone and glycolaldehyde are primarily oxidation products. Acetaldehyde is well-known to derive from the stable intermediate hydroxyacetone, thus its formation requires additional heat. ${ }^{44}$ 
Table 4. Gas-Phase Reaction Equilibrium Constants $\left(K_{\mathrm{eq}}\right)$ as a Function of Temperature

\begin{tabular}{|c|c|c|c|c|c|c|}
\hline equation & reaction & $423 \mathrm{~K}$ & $473 \mathrm{~K}$ & $523 \mathrm{~K}$ & $573 \mathrm{~K}$ & $623 \mathrm{~K}$ \\
\hline 1 & $\mathrm{PG} \leftrightharpoons$ propanal $+\mathrm{H}_{2} \mathrm{O}$ & $4.81 \mathrm{E}+07$ & $4.09 \mathrm{E}+07$ & $3.60 \mathrm{E}+07$ & $3.23 \mathrm{E}+07$ & $9.50 \mathrm{E}+08$ \\
\hline 2 & $\mathrm{GLY} \leftrightharpoons$ acrolein $+2 \mathrm{H}_{2} \mathrm{O}$ & $6.81 \mathrm{E}+12$ & $1.19 \mathrm{E}+13$ & $1.90 \mathrm{E}+13$ & $2.85 \mathrm{E}+13$ & $4.23 E+16$ \\
\hline 3 & $\mathrm{GLY} \leftrightharpoons$ hydroxyacetone $+\mathrm{H}_{2} \mathrm{O}$ & $4.97 \mathrm{E}+10$ & $2.12 \mathrm{E}+10$ & $1.07 \mathrm{E}+10$ & $6.06 \mathrm{E}+09$ & $1.22 \mathrm{E}+11$ \\
\hline 4 & hydroxyacetone $\leftrightharpoons$ formaldehyde + acetaldehyde & $2.52 \mathrm{E}-03$ & $2.79 \mathrm{E}-02$ & $1.93 \mathrm{E}-01$ & $9.47 \mathrm{E}-01$ & $3.56 \mathrm{E}+00$ \\
\hline 5 & glycolaldehyde $\leftrightharpoons 2$ formaldehyde & $2.01 \mathrm{E}-03$ & $2.00 \mathrm{E}-02$ & $1.27 \mathrm{E}-01$ & $5.79 \mathrm{E}-01$ & $2.05 \mathrm{E}+00$ \\
\hline
\end{tabular}

Table 5. Gas-Phase Equilibrium Composition on a Mole Fraction Basis $\left(x_{i, g}\right)$ as a Function of Temperature ${ }^{a}$

$\begin{array}{cccccc}\text { compound } & 423 \mathrm{~K} & 473 \mathrm{~K} & 523 \mathrm{~K} & 573 \mathrm{~K} & 623 \mathrm{~K} \\ \mathrm{PG} & 0.29 & 0.48 & 0.62 & 0.70 & 0.73 \\ \mathrm{GLY} & 0.01 & 0.02 & 0.04 & 0.08 & 0.12 \\ \mathrm{H}_{2} \mathrm{O} & 0.70 & 0.51 & 0.34 & 0.22 & 0.15\end{array}$

${ }^{a}$ Vapor pressures were calculated using Antoine vapor pressure parameters and enthalpy of vaporization values from the NIST Chemistry webbook. ${ }^{47}$

the highest device power and at the airflow rates of 12.5-16.7 $\mathrm{mL} / \mathrm{s}^{35}$ Figure 1 shows that the KangerTech Subtank Mini used in the study herein consumes $\leq 11 \mathrm{mg} /$ puff of PG/GLY only at wattages lower than those that are typically used by most vapers. ${ }^{58}$

The intake of e-liquid solvent by a user can markedly increase not only as a function of power settings but also as a function of airflow (Figure 1). PG and GLY are generally recognized as safe (GRAS) for human consumption. For ingestion via food, the World Health Organization recommends an average daily intake (ADI) maximum of $25 \mathrm{mg} / \mathrm{kg}$ of body weight for PG. ${ }^{51}$ However, the inhalation toxicity of PG and GLY based on exposure to humans is not established. Thus, PG and GLY have been assigned the default occupational $8 \mathrm{~h}$ threshold limit values of $10 \mathrm{mg} / \mathrm{m}^{3}{ }^{52}$

For a $70 \mathrm{~kg}$ human, $1750 \mathrm{mg}(70 \mathrm{~kg} \times 25 \mathrm{mg} / \mathrm{kg} /$ day $)$ corresponds to the ADI maximum PG intake/day by ingestion (i.e., GRAS), not inhalation. At the power level of $24 \mathrm{~W}$, which is within the manufacturer's recommended range for the ecigarette used herein, ${ }^{50}$ at a relatively modest airflow of 18.3 $\mathrm{mL} / \mathrm{s}$, Figure 1 shows that $18.50 \mathrm{mg}$ of PG/GLY is consumed. At 200 puffs/day (Table 1), a user would thus inhale $3700 \mathrm{mg} /$ day of 1:1 PG/GLY. At 200 puffs/day and a $36.0 \mathrm{~mL} / \mathrm{s}$ flow rate, $5660 \mathrm{mg}$ 1:1 PG:GLY is inhaled. Assuming 50\% of the aerosol is $\mathrm{PG}$ (and this percentage can be higher or lower in commercial e-liquids), these inhalation values are in range of the GRAS maximum levels for PG in food.

The National Aeronautics and Space Administration has calculated a Spacecraft Maximum Acceptable Concentration (SMAC) for PG of $32 \mathrm{ppm}$ for $1 \mathrm{~h}$, based on the calculations from a study involving human subjects. ${ }^{53}$ Using the physiological daily inhalation rate of $17.48 \mathrm{~m}^{3} /$ day $^{54}(0.7283$ $\mathrm{m}^{3} / \mathrm{h}$ ) to estimate the breath volume for a 23-30 year old adult males, affords $75 \mathrm{mg}$ PG (using $1 \mathrm{ppm}=3.2 \mathrm{mg} / \mathrm{m}^{3}$ conversion) $)^{53}$ as the maximum SMAC limit per hour. According to Figure 1, the e-cigarette used in this study at $24 \mathrm{~W}$ delivers $18.50 \mathrm{mg} /$ puff and $28.30 \mathrm{mg} /$ puff at airflow rates of 18.3 and $36.0 \mathrm{~mL} / \mathrm{s}$, respectively. At $25 \mathrm{puffs} / \mathrm{h}$, the PG/GLY inhaled at $18.3 \mathrm{~mL} / \mathrm{s}$ is $462.5 \mathrm{mg} / \mathrm{h}$. If $50 \%$ of the aerosol is PG, and assuming $~ 50 \%$ of the PG is exhaled, a user would be exposed to $115.6 \mathrm{mg}$ PG/h (not accounting for any possible aerosol re-inhaled after release into a room). The corresponding level of PG consumed in $1 \mathrm{~h}$ at the $36.0 \mathrm{~mL} / \mathrm{s}$ flow rate is $176.9 \mathrm{mg}$. Each estimate exceeds the $75 \mathrm{mg}$ SMAC value, does not take into account any effect of GLY, and assumes $50 \%$ of the PG is exhaled, though it is reportedly absorbed rapidly. ${ }^{55}$ The absorption of e-cigarette aerosols will also be higher when users engage in "stealth vaping," which can involve more intense inhalation and longer lung retention. ${ }^{56}$ Importantly, the device used in this study may underestimate the amount of aerosol inhaled compared to the lower resistance sub-ohm coils.

The potential harm of PG/GLY in e-cigarettes has been reported previously; however, only e-cigarettes available up until 2013 were considered. ${ }^{57}$ The older devices delivered less e-liquid as aerosol as compared to current generation (e.g., sub-ohm) e-cigarettes. In addition, in 2013, an extreme volume of e-liquid consumed per day was considered to be $5-25 \mathrm{~mL} /$ day; ${ }^{57}$ however, several vapers reported in a 2016 forum that they consume $\geq 25 \mathrm{~mL} /$ day. ${ }^{58}$ Many e-cigarettes with improved wicking and heat transfer properties are now on

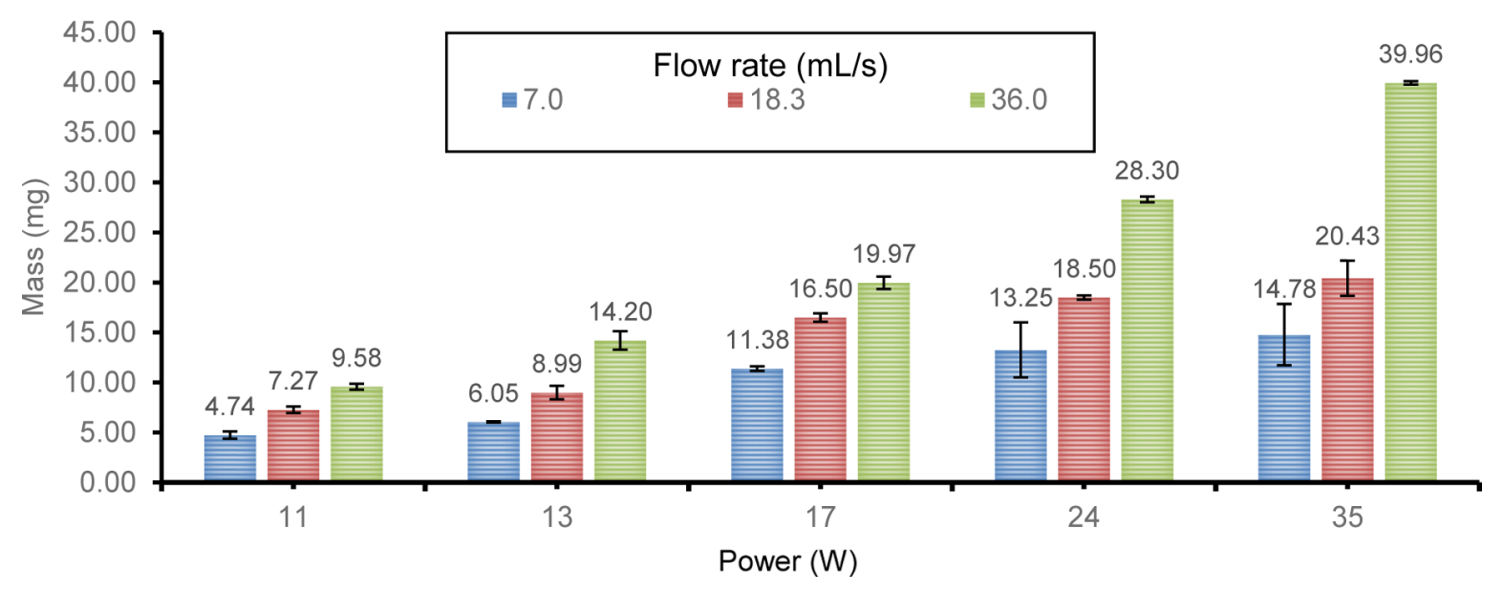

Figure 1. E-Liquid Consumption Per Puff as a Function of Power (mL/s): Flow Rate-Dependent Pattern. 
the market, including those enabling enhanced airflow. Limited studies to date have shown promising results in suppressing aldehyde-derived aerosol degradation product levels. ${ }^{30}$ However, such devices also deliver higher levels of PG and GLY, which should be taken into account when assessing frequency of use and potential toxicity.

\section{CONCLUSIONS}

A main outcome of this study is that aerosol product profiles change as a function of airflow rates. Because slower airflow leads to higher heating coil temperatures, thermal dehydration products form more readily. In a similar manner, oxidation products form at relatively greater levels when airflow is increased. Because airflow influences individual aerosol product levels when keeping other variables constant, it should be accounted for when comparing intra- and interlaboratory studies of toxicant levels (Table S1, Supporting Information). For example, experimental airflow rates have, to date, varied widely among research studies (from 8 to $39 \mathrm{~mL} / \mathrm{s}$; Table 2). It is difficult to be certain of a clear trend just based on the literature to date due to the other experimental variables that differ among laboratories. Interestingly, relatively very low levels of aldehydes have been observed as PG and GLY decomposition products in studies that employed the highest flow rates $\left(39 \mathrm{~mL} / \mathrm{s}\right.$; see Table 2). ${ }^{32,33}$ The second main outcome of this investigation is the finding that e-cigarette solvent consumption increases significantly with increased airflow. Increased airflow is a main factor enabling vapers to achieve larger aerosol clouds but also facilitates reaching threshold dietary safety levels of e-cigarette solvent consumption. This is particularly concerning due to the popularity of DLI vaping and cloud tricks among young people.

\section{METHODS}

Materials and Equipment. The brand and type of battery unit and atomizer were chosen based on availability and popularity. The electronic cigarette consisted of a variable voltage battery unit Tesla Invader III with two 18650 HG2 LG batteries (3.7 V, $3000 \mathrm{mAh}$ ) and a KangerTech SubTank Mini atomizer referred as a popular device with operational power of $15-30 \mathrm{~W}^{50}$ The atomizer included a KangerTech "OCC" coil housing, which was rebuilt with a single bottom horizontal heating element. Twenty-eight AWG A1 kanthal wire was used to construct the single bottom coils with a $1.26 \pm 0.06 \Omega$ resistance. E-liquid was prepared by adding equimolar amounts of GLY and PG (0.2 moles of each reagent, $18.4180 \mathrm{~g}$ of GLY and $15.2180 \mathrm{~g}$ of $\mathrm{PG}$ ) to a tared $50 \mathrm{~mL}$ flask, with subsequent mixing and vortexing.

Aerosol Production for Toxicant Analysis. PG and GLY decomposition product profiles were investigated as a function of flow rate. Other variables such as coil type, e-cigarette, and e-liquid composition were fixed in all of the experiments. Aerosol was produced by a Single Cigarette Smoking Machine SCSM-STEP (SCSM-STEP, CH Technologies, Westwood, $\mathrm{NJ}$ ), using two vaping modes, CORESTA (3 s puff duration, $30 \mathrm{~s}$ puff interval, $55 \mathrm{~mL}$ puff volume) and Custom Square Mode (3 s puff duration, $30 \mathrm{~s}$ puff interval, $21 \mathrm{~mL}$ puff volume), corresponding to flow rates of 18.3 and $7.0 \mathrm{~mL} / \mathrm{s}$, respectively. ${ }^{59}$ The e-cigarette was operated manually with a 1 $s$ power button activation before vaping. In the experimental setup, the aerosol generated by the electronic cigarette was drawn into an impinger containing DMSO- $d_{6}$ followed by a
$-78{ }^{\circ} \mathrm{C}$ cold trap (dry ice/acetone) connected to the SCSMSTEP Machine (Figure S1, Supporting Information). Triplicate experiments with two variable flow rates were performed for the following wattages: $11,13,17,24$, and $35 \mathrm{~W}$.

Avoidance of Dry Coil and Overheated E-Liquid. Atomizers were filled to $2 / 3$ of their tank capacity to avoid drying and overheating the coil and burning the e-liquid; wicks were primed before use (as per manufacturer's instructions) by directly wetting with e-liquid. Coils were inspected after each vaping session and reused up to 100 puffs. Replicates were discarded if any signs of dry coil were observed, including but not limited to wicking material discoloration, coil discoloration, or burnt sample odor. Overall, two replicates were discarded due to wick discoloration from a white to a slightly yellow color in experiments at 11-24 W; experiments at $35 \mathrm{~W}$ were discarded due to a potentially dry coil and burnt e-liquid.

Quantification Methods and Analytical Determination of Vapor Composition. Previously, we used quantitative NMR (qNMR) for analyzing e-cigarette aerosol toxins. This enabled the discovery of previously unreported e-cigarette aerosol components. In a recent paper, ${ }^{60}$ we validated the qNMR method including comparison to the U.S. EPA standard methods. Our rationale for using NMR in e-cigarette work is (i) NMR is a chemically nondestructive method and (ii) e-cigarette aerosols contain both gas phase and particulate phases, and our sample collection method combined with NMR allows profiling of analytes partitioned into both phases.

During each vaping session, 20 puffs were collected. Each session was followed by washing the cold trap with aliquots of impinger solution. Samples for ${ }^{1} \mathrm{H}$ NMR spectroscopy were prepared from the combination of the total impinger solution plus the solution of cold trap washes. ${ }^{1} \mathrm{H}$ NMR spectra (Figures S3-S5, Supporting Information) were acquired on a Bruker Avance II $+400 \mathrm{MHz}$ spectrometer using a zg30 pulse program, a 60.0 s relaxation delay and 1024 scans. The analyte signals were integrated with respect to the internal standard (2,3,5,6-tetrachloronitrobenzene; Tokyo Chemical Industry Co., LTD) signal at $\sim 8.5 \mathrm{ppm}$.

The mass yield of each analyte was calculated using their integral areas $\left(I_{\mathrm{x}}\right.$ and $\left.I_{\text {std }}\right)$, the molar masses $\left(M_{\mathrm{x}}\right)$, and the numbers of nuclei $\left(N_{\mathrm{x}}\right.$ and $\left.N_{\text {std }}\right)$ with respect to weight $\left(W_{\text {std }}\right)$ of the internal standard using the following equation

where $\mathrm{x}$ and std are referred to the analyte and the standard, respectively.

Experiments at 11-17 W showed toxicants with concentrations lower than limit of quantitation and limit of detection (Table S2, Supporting Information).

Aerosol Production for E-Liquid Consumption Analysis. SCSM-STEP was operated under three vaping modes: CORESTA ( $3 \mathrm{~s}$ puff duration, $30 \mathrm{~s}$ puff interval, $55 \mathrm{~mL}$ puff volume) and two Custom Square Modes (3 s puff duration, 30 s puff interval, 108 and $21 \mathrm{~mL}$ puff volumes), corresponding to flow rates of $18.3,36.0$, and $7.0 \mathrm{~mL} / \mathrm{s}$, respectively. ${ }^{59}$ The mass of consumed e-liquid was recorded by weighing the atomizer before and after vaping. 


\section{ASSOCIATED CONTENT}

\section{S Supporting Information}

The Supporting Information is available free of charge on the ACS Publications website at DOI: 10.1021/acsomega.7b01521.

Additional experimental data and procedures (PDF)

\section{AUTHOR INFORMATION}

\section{Corresponding Author}

*E-mail: strongin@pdx.edu.

\section{ORCID}

Kelley C. Barsanti: 0000-0002-6065-8643

Robert M. Strongin: 0000-0003-3777-8492

\section{Author Contributions}

All authors contributed equally.

\section{Notes}

The authors declare no competing financial interest.

\section{ACKNOWLEDGMENTS}

We thank the NIH and the FDA for their support via award R01ES025257. The content is solely the responsibility of the authors and does not necessarily represent the views of the $\mathrm{NIH}$ or the FDA. We express sincere appreciation to Dr. Elliot Mylott and Kevin McWhirter for generosity with their time and knowledge.

\section{ABBREVIATIONS}

PG, propylene glycol; GLY, glycerol; DLI, direct lung inhalation; MTL, mouth-to-lung; SMAC, spacecraft maximum acceptable concentration; GRAS, generally recognized as safe

\section{REFERENCES}

(1) Reitsma, M. B.; Fullman, N.; Ng, M.; Salama, J. S.; Abajobir, A.; Abate, K. H.; Abbafati, C.; Abera, S. F.; Abraham, B.; Abyu, G. Y.; Adebiyi, A. O.; Al-Aly, Z.; Aleman, A. V.; Ali, R.; Al Alkerwi, A.; Allebeck, P.; Al-Raddadi, R. M.; Amare, A. T.; Amberbir, A.; Ammar, W.; Amrock, S. M.; Antonio, C. A. T.; Asayesh, H.; Atnafu, N. T.; Azzopardi, P.; Banerjee, A.; Barac, A.; Barrientos-Gutierrez, T.; BastoAbreu, A. C.; Bazargan-Hejazi, S.; Bedi, N.; Bell, B.; Bello, A. K.; Bensenor, I. M.; Beyene, A. S.; Bhala, N.; Biryukov, S.; Bolt, K.; Brenner, H.; Butt, Z.; Cavalleri, F.; Cercy, K.; Chen, H. L.; Christopher, D. J.; Ciobanu, L. G.; Colistro, V.; Colomar, M.; Cornaby, L.; Dai, X. C.; Damtew, S. A.; Dandona, L.; Dandona, R.; Dansereau, E.; Davletov, K.; Dayama, A.; Degfie, T. T.; Deribew, A.; Dharmaratne, S. D.; Dimtsu, B. D.; Doyle, K. E.; Endries, A. Y.; Ermakov, S. P.; Estep, K.; Faraon, E. J. A.; Farzadfar, F.; Feigin, V. L.; Feigl, A. B.; Fischer, F.; Friedman, J.; Ghiwot, T. T.; Gall, S. L.; Gao, W. N.; Gillum, R. F.; Gold, A. L.; Gopalani, S. V.; Gotay, C. C.; Gupta, R.; Gupta, R.; Gupta, V.; Hamadeh, R. R.; Hankey, G.; Harb, H. L.; Hay, S. I.; Horino, M.; Horita, N.; Hosgood, H. D.; Husseini, A.; Ileanu, B. V.; Islami, F.; Jiang, G. H.; Jiang, Y.; Jonas, J. B.; Kabir, Z.; Kamal, R.; Kasaeian, A.; Kesavachandran, C. N.; Khader, Y. S.; Khalil, I.; Khang, Y. H.; Khera, S. Smoking prevalence and attributable disease burden in 195 countries and territories, 1990-2015: a systematic analysis from the Global Burden of Disease Study 2015. Lancet 2017, 389, 1885-1906.

(2) Preventing Tobacco Use Among Youth and Young Adults: A Report of the Surgeon General, Atlanta, GA; US Department of Health and Human Services, Centers for Disease Control and Prevention, National Center for Chronic Disease Prevention and Health Promotion, Office on Smoking and Health, 2012; p 3.

(3) Singh, T.; Arrazola, R. A.; Corey, C. G.; Husten, C. G.; Neff, L. J.; Homa, D. M.; King, B. A. Tobacco use among middle and high school students - United States, 2011-2015. Morb. Mortal. Wkly. Rep. 2016, 65, 361-367.

(4) Murthy, V. H. E-cigarette use among youth and young adults: A major public health concern. JAMA Pediatr. 2017, 171, 209-210.

(5) Westling, E.; Rusby, J. C.; Crowley, R.; Light, J. M. Electronic Cigarette Use by Youth: Prevalence, Correlates, and Use Trajectories From Middle to High School. J. Adolesc. Health 2017, 60, 660-666.

(6) Soneji, S.; Barrington-Trimis, J. L.; Wills, T. A.; Leventhal, A. M.; Unger, J. B.; Gibson, L. A.; Yang, J.; Primack, B. A.; Andrews, J. A.; Miech, R. A.; Spindle, T. R.; Dick, D. M.; Eissenberg, T.; Hornik, R. C.; Dang, R.; Sargent, J. D. Association between initial use of ecigarettes and subsequent cigarette smoking among adolescents and young adults: A systematic review and meta-analysis. JAMA Pediatr. 2017, 171, 788-797.

(7) Goniewicz, M. L.; Gawron, M.; Smith, D. M.; Peng, M.; Jacob, I. I. I. P.; Benowitz, N. L. Exposure to Nicotine and Selected Toxicants in Cigarette Smokers Who Switched to Electronic Cigarettes: A Longitudinal Within-Subjects Observational Study. Nicotine Tob. Res. 2017, 19, 160-167.

(8) Dautzenberg, B. Real-time characterization of e-cigarettes use: The 1 million puffs study. J. Addict. Res. Ther. 2015, 06, 229.

(9) Behar, R. Z.; Hua, M.; Talbot, P. Puffing topography and nicotine intake of electronic cigarette users. PLoS One 2015, 10, No. e0117222.

(10) Dawkins, L.; Turner, J.; Roberts, A.; Soar, K. 'Vaping' profiles and preferences: an online survey of electronic cigarette users. Addiction 2013, 108, 1115-1125.

(11) Etter, J.-F.; Bullen, C. A longitudinal study of electronic cigarette users. Addict. Behav. 2014, 39, 491-494.

(12) Farsalinos, K. E.; Romagna, G.; Tsiapras, D.; Kyrzopoulos, S.; Voudris, V. Evaluation of electronic cigarette use (vaping) topography and estimation of liquid consumption: Implications for research protocol standards definition and for public health authorities' regulation. Int. J. Environ. Res. Public Health 2013, 10, 2500-2514.

(13) Farsalinos, K. E.; Spyrou, A.; Stefopoulos, C.; Tsimopoulou, K.; Kourkoveli, P.; Tsiapras, D.; Kyrzopoulos, S.; Poulas, K.; Voudris, V. Nicotine absorption from electronic cigarette use: comparison between experienced consumers (vapers) and naive users (smokers). Sci. Rep. 2015, 5, No. 11269.

(14) Goniewicz, M. L.; Kuma, T.; Gawron, M.; Knysak, J.; Kosmider, L. Nicotine levels in electronic cigarettes. Nicotine Tob. Res. 2013, 15, 158-166.

(15) Hua, M.; Yip, H.; Talbot, P. Mining data on usage of electronic nicotine delivery systems (ENDS) from YouTube videos. Tob. Control 2013, 22, 103-106.

(16) Lee, Y. H.; Gawron, M.; Goniewicz, M. L. Changes in puffing behavior among smokers who switched from tobacco to electronic cigarettes. Addict. Behav. 2015, 48, 1-4.

(17) Lopez, A. A.; Eissenberg, T. Science and the evolving electronic cigarette. Prev. Med. 2015, 80, 101-106.

(18) Norton, K. J.; June, K. M.; O’Connor, R. J. Initial puffing behaviors and subjective responses differ between an electronic nicotine delivery system and traditional cigarettes. Tob. Induced Dis. 2014, 12, 17.

(19) Robinson, R. J.; Hensel, E. C.; Morabito, P. N.; Roundtree, K. A. Electronic cigarette topography in the natural environment. PLoS One 2015, 10, No. e0129296.

(20) Robinson, R. J.; Hensel, E. C.; Roundtree, K. A.; Difrancesco, A. G.; Nonnemaker, J. M.; Lee, Y. O. Week long topography study of young adults using electronic cigarettes in their natural environment. PLoS One 2016, 11, No. e0164038.

(21) Spindle, T. R.; Breland, A. B.; Karaoghlanian, N. V.; Shihadeh, A. L.; Eissenberg, T. Preliminary results of an examination of electronic cigarette user puff topography: The effect of a mouthpiecebased topography measurement device on plasma nicotine and subjective effects. Nicotine Tob. Res. 2015, 17, 142-149.

(22) Measham, F.; O’Brien, K.; Turnbull, G. "Skittles \& Red Bull is my favourite flavour": E-cigarettes, smoking, vaping and the changing landscape of nicotine consumption amongst British teenagers - 
implications for the normalisation debate. Drugs: Educ. Prev. Polic. 2016, 23, 224-237.

(23) Ranosa, T. What Lures Teens into Using E-Cigarettes? Flavors and Smoke Tricks. Tech Times http://www.techtimes.com/articles/ 50313/20150503/what-lures-teens-into-using-e-cigarettes-smoketricks-here-are-some-examples-and-tutorials-videos.htm (accessed Aug 27, 2017).

(24) Doward, J.; Agerholm, H. It's Not Nicotine, It's the Smoke Tricks Young Vapers Love. https://www.theguardian.com/society/ 2016/may/14/vaping-not-nicotine-tricks-young-vapers (accessed Aug 27, 2017).

(25) Fox, L. 9 Ways to Improve Vapor Production from your e-Cig. http://ecigarettereviewed.com/9-ways-to-improve-vapor-productionfrom-your-e-cig/ (accessed Aug 15, 2017).

(26) Williams, M.; Talbot, P. Variability among electronic cigarettes in the pressure drop, airflow rate, and aerosol production. Nicotine Tob. Res. 2011, 13, 1276-1283.

(27) Zhao, T.; Shu, S.; Guo, Q.; Zhu, Y. Effects of design parameters and puff topography on heating coil temperature and mainstream aerosols in electronic cigarettes. Atmos. Environ. 2016, 134, 61-69.

(28) Sleiman, M.; Logue, J. M.; Montesinos, N. V.; Russell, M. L.; Litter, M. I.; Gundel, L. A.; Destaillats, H. Emissions from electronic cigarettes: Key parameters affecting the release of harmful chemicals. Environ. Sci. Technol. 2016, 50, 9644-9651.

(29) Geiss, O.; Bianchi, I.; Barrero-Moreno, J. Correlation of volatile carbonyl yields emitted by e-cigarettes with the temperature of the heating coil and the perceived sensorial quality of the generated vapours. Int. J. Hyg. Environ. Health 2016, 219, 268-277.

(30) Gillman, I. G.; Kistler, K. A.; Stewart, E. W.; Paolantonio, A. R. Effect of variable power levels on the yield of total aerosol mass and formation of aldehydes in e-cigarette aerosols. Regul. Toxicol. Pharmacol. 2016, 75, 58-65.

(31) Tayyarah, R.; Long, G. A. Comparison of select analytes in aerosol from e-cigarettes with smoke from conventional cigarettes and with ambient air. Regul. Toxicol. Pharmacol. 2014, 70, 704-710.

(32) Kosmider, L.; Sobczak, A.; Fik, M.; Knysak, J.; Zaciera, M.; Kurek, J.; Goniewicz, M. Carbonyl compounds in electronic cigarette vapors: Effects of nicotine solvent and battery output voltage. Nicotine Tob. Res. 2014, 16, 1319-1326.

(33) Goniewicz, M. L.; Knysak, J.; Gawron, M.; Kosmider, L.; Sobczak, A.; Kurek, J.; Prokopowicz, A.; Jablonska-Czapla, M.; RosikDulewska, C.; Havel, C.; Jacob, P.; Benowitz, N. Levels of selected carcinogens and toxicants in vapour from electronic cigarettes. Tob. Control 2013, 23, 133-139.

(34) Hutzler, C.; Paschke, M.; Kruschinski, S.; Henkler, F.; Hahn, J.; Luch, A. Chemical hazards present in liquids and vapors of electronic cigarettes. Arch. Toxicol. 2014, 88, 1295-1308.

(35) Jensen, R. P.; Luo, W.; Pankow, J. F.; Strongin, R. M.; Peyton, D. H. Hidden formaldehyde in e-cigarette aerosols. N. Engl. J. Med. 2015, 372, 392-394.

(36) Uchiyama, S.; Ohta, K.; Ina, Y.; Kunugita, N. Determination of carbonyl compounds generated from the e-cigarette using coupled silica cartridges impregnated with hydroquinone and 2,4-dinitrophenylhydrazine, followed by high-performance liquid chromatography. Anal. Sci. 2013, 29, 1219-1222.

(37) McAuley, T. R.; Hopke, P. K.; Zhao, J.; Babaian, S. Comparison of the effects of e-cigarette vapor and cigarette smoke on indoor air quality. Inhalation Toxicol. 2012, 24, 850-857.

(38) Laugesen, M. Nicotine and toxicant yield ratings of electronic cigarette brands in New Zealand. N. Z. Med. J. 2015, 128, 77-82.

(39) Khlystov, A.; Samburova, V. Flavoring compounds dominate toxic aldehyde production during e-cigarette vaping. Environ. Sci. Technol. 2016, 50, 13080-13085.

(40) Uchiyama, S.; Inaba, Y.; Kunugita, N. Determination of acrolein and other carbonyls in cigarette smoke using coupled silica cartridges impregnated with hydroquinone and 2,4-dinitrophenylhydrazine. $J$. Chromatogr. A 2010, 1217, 4383-4388.
(41) Ogunwale, M. A.; Li, M.; Raju, M. V.; Chen, Y.; Nantz, M. H.; Conklin, D. J.; Fu, X.-A. Aldehyde detection in electronic cigarette aerosols. ACS Omega 2017, 2, 1207-1214.

(42) Talih, S.; Balhas, Z.; Salman, R.; Karaoghlanian, N.; Shihadeh, A. "Direct dripping": A high-temperature, high-formaldehyde emission electronic cigarette use method. Nicotine Tob. Res. 2016, $18,453-459$.

(43) Herrington, J. S.; Myers, C. Electronic cigarette solutions and resultant aerosol profiles. J. Chromatogr. A 2015, 1418, 192-199.

(44) Jensen, R. P.; Strongin, R. M.; Peyton, D. H. Solvent chemistry in the electronic cigarette reaction vessel. Sci. Rep. 2017, 7, No. 42549.

(45) Laino, T.; Tuma, C.; Curioni, A.; Jochnowitz, E.; Stolz, S. A revisited picture of the mechanism of glycerol dehydration. J. Phys. Chem. A 2011, 115, 3592-3595.

(46) Díaz, E.; Sad, M. E.; Iglesia, E. Homogeneous oxidation reactions of propanediols at low temperatures. ChemSusChem 2010, 3, 1063-1070.

(47) NIST Chemistry WebBook, NIST Standard Reference Database Number 69; Linstrom, P. J., Mallard, W. G., Eds.; National Institute of Standards and Technology: Gaithersburg MD, 2001.

(48) Lurie, M.; Michailoff, N. Evaporation from free water surface. Ind. Eng. Chem. 1936, 28, 345-349.

(49) Molstad, M. C.; Farevaag, P.; Farrell, J. A. Rate of evaporation from a free water surface by a perpendicular air stream. Ind. Eng. Chem. 1938, 30, 1131-1138.

(50) Farsalinos, K. E.; Yannovits, N.; Sarri, T.; Voudris, V.; Poulas, $K$. Protocol proposal for, and evaluation of, consistency in nicotine delivery from the liquid to the aerosol of electronic cigarettes atomizers: regulatory implications. Addiction 2016, 111, 1069-1076.

(51) World Health Organization. Evaluations of the Joint FAO/ WHO Expert Committee on Food Additives (JECFA). c2002. http:// apps.who.int/food-additives-contaminants-jecfa-database/chemical. aspx? chemID $=2698$ (accessed Aug 15, 2017).

(52) ACGIH. TLVs and BEIs Based on the Documentation of the Threshold Limit Values for Chemical Substances and Physical Agents \& Biological Exposure Indices; ACGIH: Cincinnati, OH, 2012.

(53) Spacecraft Maximum Allowable Concentrations for Selected Airborne Contaminants; Crossgrove, R. E., Ed.; The National Academies Press: Washington, DC, 2008; Vol. 5.

(54) U.S. EPA. Exposure Factors Handbook 2011 Edition (Final Report), EPA/600/R-09/052F; U.S. Environmental Protection Agency: Washington, DC, 2011.

(55) Schripp, T.; Markewitz, D.; Uhde, E.; Salthammer, T. Does ecigarette consumption cause passive vaping? Indoor Air 2013, 23, 2531 .

(56) Jones, I. Stealth Vaping 101: How to Become a Vaping Ninja http://vaping360.com/stealth-vaping/ (accessed Aug 27, 2017).

(57) Burstyn, I. Peering through the mist: systematic review of what the chemistry of contaminants in electronic cigarettes tells us about health risks. BMC Public Health 2014, 14, 18.

(58) How Much ml of Juice you Vape a Day? Vaping Underground; c2016. http://vapingunderground.com/threads/how-much-ml-ofjuice-you-vape-a-day.254169/ (accessed Aug 27, 2017).

(59) CORESTA Recommended Method No 81: Routine Analytical Machine for E-Cigarette Aerosol Generation and Collection Definitions and Standard Conditions. https://www.coresta.org/ routine-analytical-machine-e-cigarette-aerosol-generation-andcollection-definitions-and-standard (accessed Sept 1, 2016).

(60) Salamanca, J. C.; Munhenzva, I.; Escobedo, J. O.; Jensen, R. P.; Shaw, A.; Campbell, R.; Luo, W.; Peyton, D. H.; Strongin, R. M. Formaldehyde Hemiacetal Sampling, Recovery, and Quantification from Electronic Cigarette Aerosols. Sci. Rep. 2017, 7, No. 11044. 